\title{
Utilizing Incomplete Phase Transformation to Characterize Elastocaloric Effect of Shape Memory Alloys
}

\author{
Liu, Zhe; Liang, Jierong; Huang, Chaiyi; Li, Tingxun
}

Published in:

Energy Technology

Link to article, DOI:

10.1002/ente.202000322

Publication date:

2020

Document Version

Peer reviewed version

Link back to DTU Orbit

Citation (APA):

Liu, Z., Liang, J., Huang, C., \& Li, T. (2020). Utilizing Incomplete Phase Transformation to Characterize Elastocaloric Effect of Shape Memory Alloys. Energy Technology, 8(9), [2000322].

https://doi.org/10.1002/ente.202000322

\section{General rights}

Copyright and moral rights for the publications made accessible in the public portal are retained by the authors and/or other copyright owners and it is a condition of accessing publications that users recognise and abide by the legal requirements associated with these rights.

- Users may download and print one copy of any publication from the public portal for the purpose of private study or research.

- You may not further distribute the material or use it for any profit-making activity or commercial gain

- You may freely distribute the URL identifying the publication in the public portal

If you believe that this document breaches copyright please contact us providing details, and we will remove access to the work immediately and investigate your claim. 


\section{Utilizing incomplete phase transformation to characterize elastocaloric effect of}

\section{shape memory alloys}

Zhe Liu, ${ }^{1}$ Jierong Liang, ${ }^{2}$ Chaiyi Huang, ${ }^{1}$ Tingxun $L i^{1, *}$

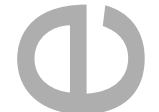

${ }^{1}$ School of Intelligent Systems Engineering, Sun Yat-sen University, West XINGANG Road 135, Guangzhou 510275, China

${ }^{2}$ Department of Energy Conversion and Storage, Technical University of Denmark, Anker Engelunds Vej, 2800 Kgs. Lyngby, Denmark

*Corresponding Author:

Tel: (+86) 0203933 3115, E-mail: litx@ mail.sysu.edu.cn

Keywords: Elastocaloric effect, Incomplete phase transformation, Latent heat, Shape memory alloys

\section{Abstract}

This study reported a correction to assist the elastocaloric effect characterization of shape memory alloys and obtain the latent heat of stress-induced martensitic transformation. The incomplete phase transformation analysis (IPTA) correction was developed based on the assumptions of linear transformation plateau of stress-strain and identical heat capacities for austenite and martensite phases. Taking $\mathrm{Ni}_{50.8} \mathrm{Ti}_{49.2}$ alloy as a demonstration, an integrated test rig was built to validate IPTA correction and study the heat leak effect. Using water as heat transfer fluid and heat leak compensation are able to further improve the accuracy of imposing IPTA correction. The predictions of latent heat from direct and indirect approaches with IPTA correction are well validated from the experimental data. The required minimum martensitic phase fraction is only 10-20\% when applying the IPTA correction, compared to $84-93 \%$ in traditional approaches. The IPTA correction extended

This article has been accepted for publication and undergone full peer review but has not been through the copyediting, typesetting, pagination and proofreading process, which may lead to differences between this version and the Version of Record. Please cite this article as doi: $10.1002 /$ ente.202000322. 
the precondition of complete transformation to incomplete transformation in elastocaloric characterization.

\section{Introduction}

Conventional vapor compression cooling technologies relying on gaseous refrigerant face more and more stress at atmosphere environment influences. Recently, solid state refrigeration technologies based on caloric effects, such as magnetocaloric ${ }^{[1]}$, electrocaloric ${ }^{[2]}$, barocaloric ${ }^{[3]}$, and elastocaloric $^{[4]}$, have drawn more attentions due to their potentially high efficiency and eco-friendliness. ${ }^{[5]}$ As the most promising alternatives to conventional refrigeration from an energy savings standpoint, ${ }^{[6]}$ elastocaloric cooling is still at the very beginning of development from the scientific and industrial perspectives. ${ }^{[7]}$

Elastocaloric cooling based on the elastocaloric effect $(\mathrm{eCE})^{[8]}$ associates with the superelasticity of shape memory alloys (SMAs). Decades of research have confirmed that the temperature change caused by a conventional caloric effect (including eCE) is limited ${ }^{[9,10]}$. Configurations of high field $^{[11]}$ and giant caloric effect ${ }^{[8,12-14]}$ can directly improve the temperature change at the expenses of significantly irreversible heat transfer losses. To effectively utilize the caloric effect in a required temperature span compared to in conventional cooling, heat-recovery, ${ }^{[15]}$ active regenerative ${ }^{[16]}$ and cascade $^{[17,18]}$ cycles are applied to execute a multi-stage of caloric refrigeration cycles ${ }^{[19-21]}$ As most caloric devices configured with active regeneration, ${ }^{[22,23]}$ SMAs can be operated in an active elastocaloric cycle as follows: 1) loading from an austenitic to a martensitic phase; 2) releasing heat crossed by fluid flow under stress; 3) unloading from a martensitic to an austenitic phase; and 4) absorbing heat during a reverse fluid flow under the stress-free condition. ${ }^{[24]}$

The eCE is commonly characterized by adiabatic temperature change $\left(\Delta T_{\text {adi }}\right)$ and isothermal entropy change $\left(\Delta s_{\text {iso }}\right)$ as a function of temperature and applied stress/strain. ${ }^{[25]}$ The characterization of caloric effect parameters are classified as direct and indirect approaches. ${ }^{[26,27]}$ The promising direct approaches can be exemplified as 1) $\Delta s_{\text {iso }}$ and $\Delta T_{\text {adi }}$ measurements via in-field calorimetry, ${ }^{[28-30]} 2$ ) $\Delta T_{\text {adi }}$ measurement by thermoacoustic method, ${ }^{[31]}$ and 3) $\Delta T_{\text {adi }}$ measurement by thermography. ${ }^{[32]}$ The indirect approaches measure the characteristics of the applied field and its conjugate variable, i.e. magnetic field strength and magnetization for magnetocaloric, and stress and strain for elastocaloric, then use these to deduce the caloric effect parameters. Most characterization approaches focused on magnetocaloric, and these concepts can be extended to elastocaloric. However, the practice to This article is protected by copyright. All rights reserved 
appropriately inherit the magnetocaloric characterization approaches still encounters several challenges.

Owing to the dynamic effect ${ }^{[27]}$, the measurements of $\Delta T_{\text {adi }}$ and $\Delta s_{\text {iso }}$ normally exhibit a degradation with increasing cycles until a certain number of cycles complete. ${ }^{[33]}$ Furthermore, the measurement of $\Delta T_{\text {adi }}$ is influenced significantly by the operating rate due to the non-thermal equilibrium. ${ }^{[34]}$ Consequently, the measurements of $\Delta T_{\text {adi }}$ and $\Delta s_{\text {iso }}$ are not only dependent on applied field strength, but also dependent on operating rate or frequency. In elastocaloric, high stress field is readily and economically accessible compared to high magnetic field in magnetocaloric. On the other hand, elastocaloric materials with large superelasticity, small hysteresis and cyclic stability, are being developed increasingly. ${ }^{[35]}$ The elastocaloric cooling has a potential to operate under nearly complete transformation. Thus, latent heat $\Delta h^{*}$ under complete phase transformation can be considered as another metric for preliminary evaluation of elastocaloric material in a cooling device. ${ }^{[36-38]}$ In practice, the $\Delta h^{*}$ can be derived by measuring the enthalpy difference and the phase fraction. ${ }^{[39]}$ The enthalpy difference under stress-free state $(\Delta h)$ is easily obtained by Differential Scanning Calorimetry (DSC). In direct approaches, it is very challenging to develop a DSC equipped with a mechanical tester due to the heat leak through the grips. ${ }^{[26]}$ Consequently, it is still difficult to measure the $\Delta h^{*}$ under stress precisely; and the phase fraction is also less measurable. Thus, most direct characterizations of the latent heat $\Delta h^{*}$ are confined to a complete phase transformation. Substantial effort is being invested in the direct approaches, which measurements can be classified into: 1) adiabatic temperature change, ${ }^{[40-42]}$ ) fluid enthalpy difference ${ }^{[43,44]}$ and 3) compensation electrical power. ${ }^{[45]}$ Although one can reduce the effect of heat leak by increasing the stress rate ${ }^{[46,47]}$ or simulating the $\Delta h^{*[45]}$, the incomplete phase transformation is disregarded in most measurements.

In indirect approaches, the $\Delta h^{*}$ is deduced using the basic thermodynamic relations, such as Maxwell relation and Clausius-Clapeyron equation. ${ }^{[48-50]}$ The preconditions for indirect approaches to correctly determine the $\Delta h^{*}$ are the accessibility of the stress-strain or strain-temperature curves associated to complete phase transformation, as well as the existence of isothermal or isostress conditions. Practical isothermal conditions can be approached by lowering the rate of stress to avoid the latent heat not to heat up the sample locally. ${ }^{[33,51,52]}$ However, SMAs with insufficient ductility are probably challenged to obtain the full stress-strain-temperature curves corresponding to complete phase transformation.

From the published data ${ }^{[8,53-59]}$ summarized in Figure 1(a), there is an obvious trend that the This article is protected by copyright. All rights reserved 
$\Delta T_{\text {adi }}$ derived from indirect approaches are larger than that derived from direct approaches. The main reasons are probably ascribed to the aforementioned imperfect thermal conditions (adiabatically or isothermally) and incomplete phase transformation. Chen et al. ${ }^{[60]}$ obtained $20 \%$ deviation between direct and indirect approaches using nanocrystalline $\mathrm{Ti}-\mathrm{Ni}-\mathrm{Cu}-\mathrm{Al}$ alloy because of the insufficient adiabatic condition. Arranging the published data of the relative deviation of the $\Delta T_{\text {adi }}$ between direct and indirect approaches, ${ }^{[33,58,59,61]}$ the deviation increases with the value of $\Delta T_{\text {adi }}$ in Figure 1(b). This implies that in many cases, the deviations are caused by the heat leaks. Imran et al. ${ }^{[62]}$ obtained a $24 \%$ deviation between the $\Delta T_{\text {adi }}$ from direct approach and that via the DSC for a $\mathrm{Ni}-\mathrm{Fe}-\mathrm{Ga}$ bulk alloy due to the incomplete phase transformation. Aaltio et al. ${ }^{[63]}$ presented a $77 \%$ deviation between the $\Delta h^{*}$ from indirect approach and $\Delta h$ from stress-free DSC in hot rolled $\mathrm{Ni}-\mathrm{Ti}$-Fe alloys due to the incomplete phase transformation. Thus, incomplete phase transformation and heat leak are the non-negligible factors for both direct and indirect approaches. Despite a number of steps are under way to reduce heat leak impacts, the focuses on the effect of incomplete phase transformation are less reported. Engelbrecht et al. ${ }^{[64]}$ analyzed the fatigue-life of the SMAs by testing $\sim 6000$ cycles before buckling. Tušek et al. ${ }^{[44]}$ limited the tension strain of Ni-Ti plates to $4 \%$ and not corresponding to a complete transformation to increase fatigue life of the device. The incomplete phase transformation is not avoidable for elastocaloric characterization.
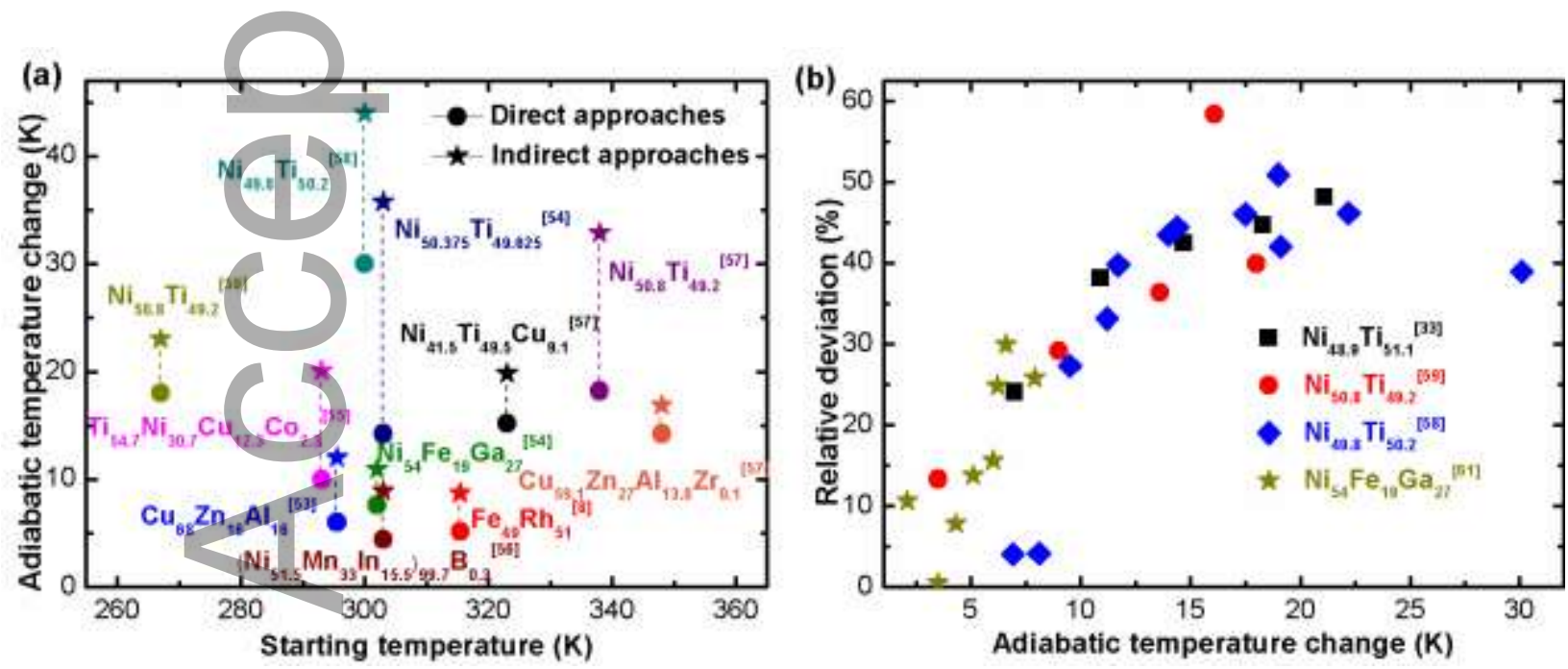

Figure 1. (a) The adiabatic temperature change of SMAs obtained from direct approaches and indirect approaches.

(b) The relative deviations of adiabatic temperature change between direct approaches and indirect approaches as a function of adiabatic temperature change of SMAs.

This study demonstrated an incomplete phase transformation analysis (IPTA) correction to This article is protected by copyright. All rights reserved 
characterize the complete phase transformation given the data of the incomplete phase transformation. The maximum elastocaloric latent heat $\Delta h^{*}$ of SMAs, which is physically from the complete transformation, was theoretically derived from released heat along an incomplete isothermal stress-induced transformation, latent heat under a stress-free temperature-induced transformation and stress-strain work. The stress-strain work was derived based on an assumption of linear transformation plateau in stress-strain relation. An integrated tester was built for validation. To reduce the experimental parasitic losses, heat transfer fluid (HTF) with large specific heat such as water was used to approach the isothermal condition, and the heat leak compensation (HLC) was included. The phase fraction of the incomplete phase transformation can be obtained via the IPTA correction, which is difficult to measure and normally neglected. IPTA correction improves the accuracy of conventional approaches and extends the elastocaloric characterization preconditions from complete transformation to incomplete transformation.

\section{Incomplete phase transformation analysis}

For a closed system in thermal equilibrium, the energy relation of a stressed SMA not only considers the PV-work but also includes the $\sigma \varepsilon$-work. PV-work is the work only interacted with the surroundings. As a basis of the IPTA correction, the specific enthalpy-like function $h^{*}$ is defined as: ${ }^{[65]}$

$h^{*}=u+p v-\sigma \varepsilon / \rho=h-\sigma \varepsilon / \rho$,

where $u, p, v, \sigma$ and $\varepsilon$ are specific internal energy, surrounding pressure, specific volume $(1 / \rho)$, external stress and strain, respectively. As will be seen below, the latent heat is a dependent variable in IPTA correction. For different external stimuli, the thermal-induced latent heat $\Delta h^{*}(T \rightarrow T+$ $\delta T, \sigma)^{[66]}$ and the stress- induced latent heat $\Delta h^{*}(T, 0 \rightarrow \sigma)^{[61]}$ are different due to the variations in martensite structure. [67] In IPTA correction, only stress-induced latent heat is predicted. The stress-induced latent heat (simplified as $\Delta h^{*}(\sigma)$ or $\Delta h^{*}$ for convention) can be derived from the latent heat under stress-free $\Delta h(T \rightarrow T+\delta T, 0)$ (simplified as $\Delta h(0))$ and the above $\sigma \varepsilon$-work $\left(w_{\sigma \varepsilon}\right){ }^{[68]}$

$\underbrace{\Delta h^{*}(\sigma)}_{\text {Latent heat }}+\underbrace{\int_{\operatorname{tran}} \sigma d \varepsilon / \rho}_{-w_{\sigma \varepsilon}}=\underbrace{\Delta h(0)+\int_{T_{0}(0)}^{T_{0}(\sigma)}\left(c_{F}^{M}-c_{F}^{P}\right) \cdot d T}_{\text {Specific enthalpy difference }} \approx \underbrace{\Delta h(0)}_{\text {Latent heat under stress-free }}$,

where $T_{0}$ and $c_{F}$ are the equilibrium temperature of transformation and the specific heat capacity of constant external force, respectively. Superscripts $\mathrm{P}$ and $\mathrm{M}$ denote the phases of parent (austenite) and This article is protected by copyright. All rights reserved 
martensite, respectively. Note that the $\sigma \varepsilon$-work along the complete martensitic transformation of stress induced, $w_{\sigma \varepsilon}=-\int_{\operatorname{tran}} \sigma d \varepsilon / \rho$, indicates the direction from the sample to the exterior. Since the transformation process is assumed isothermally and isobarically, the difference of the PV-work is eliminated. Figure 2(a) summarizes the difference between $\left|\Delta h^{*}(\sigma)-w_{\sigma \varepsilon}\right|$ and $|\Delta h(0)|$ when varying the temperatures and materials during complete phase transformation. In most cases, ${ }^{[55,69,70]}$ the difference is subtle, except at some points such as $\mathrm{Ni}_{50} \mathrm{Ti}_{50}$ in Figure 2(a) due to low transformation strain. ${ }^{[71]}$ Thus, the $\sigma \varepsilon$-work provides the possibility to connect $\Delta h^{*}(\sigma)$ and $\Delta h(0)$.
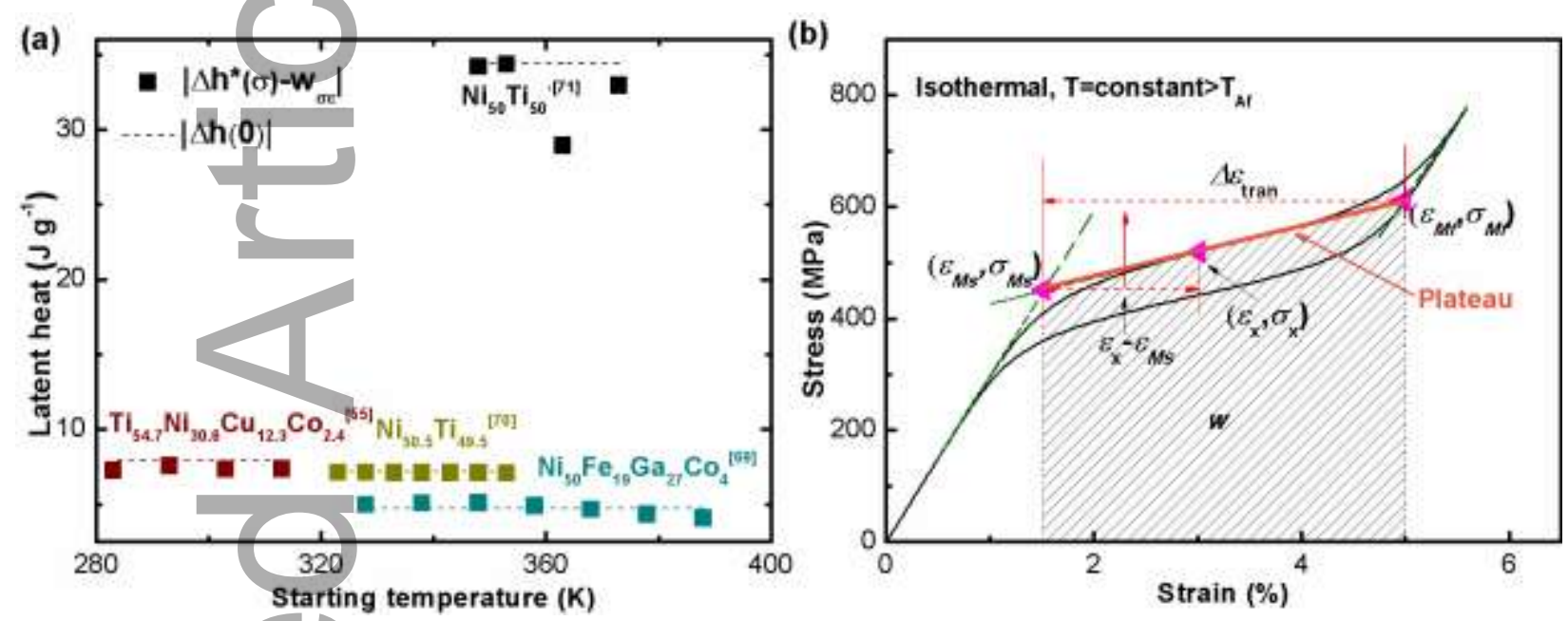

Figure 2. (a) The comparison between $\left|\Delta h^{*}(\sigma)-w_{\sigma \varepsilon}\right|$ obtained by Equation 2 and $|\Delta h(0)|$ determined by DSC under stress-free state. (b) Isothermal stress-strain curve at temperature that is higher than the austenite finish temperature $T_{\mathrm{Af}}$.

In a practical isothermal martensitic transformation, the actual released heat $q$ associated to the eCE can be expressed by the latent heat $\Delta h^{*}$ and the martensitic phase fraction $\xi_{\mathrm{M}}{ }^{[39,72]}$

$q\left(\varepsilon_{\mathrm{X}}, \sigma_{\mathrm{x}}\right)=-\xi_{\mathrm{M}} \cdot \Delta h^{*}$

where $\varepsilon_{\mathrm{x}}$ and $\sigma_{\mathrm{x}}$ are the local strain and stress along the transformation plateau, respectively. Referring to the shadow area under the stress-strain curve shown in Figure 2(b), the stress-strain relation during the transformation plateau can be assumed linearly in many commonly used SMAs, such as Ni-Ti-based, ${ }^{[33,73]} \mathrm{Cu}-\mathrm{Al}$-basd ${ }^{[53,74]}$ and Ni-Mn-based ${ }^{[38,75]}$ alloys. Thus, the $\sigma \varepsilon$-work during martensitic transformation can be expressed as:

$w_{\sigma \varepsilon}=-\int_{\operatorname{tran}} \sigma d \varepsilon / \rho=-\left(\sigma_{M s}+\sigma_{M f}\right) \Delta \varepsilon_{\operatorname{tran}} /(2 \rho)$,

where $\Delta \varepsilon_{\text {tran }}$ is the transformation strain, $\sigma_{M S}$ and $\sigma_{M f}$ are martensitic start and finish critical This article is protected by copyright. All rights reserved 
stresses, respectively. Considering the incomplete transformation point $\left(\varepsilon_{\mathrm{x}}, \sigma_{\mathrm{x}}\right)$, the slope in the transformation plateau is rewritten as:

$\frac{\sigma_{\mathrm{x}}-\sigma_{M S}}{\varepsilon_{\mathrm{X}}-\varepsilon_{M S}}=\frac{\sigma_{M f}-\sigma_{M s}}{\Delta \varepsilon_{\text {tran }}}$.

It is important to note that some SMAs exhibit nonlinear transformation plateaus $\left(\mathrm{Co}-\mathrm{Ni}-\mathrm{Al}^{[54]}\right.$ and Co-Ni- $\mathrm{Ga}^{[76]}$ ) or absence of plateaus $\left(\mathrm{Fe}-\mathrm{Pt}^{[77]}\right)$ during a phase transformation. In these cases, the IPTA correction is invalid in practice.

The martensitic phase fraction $\xi_{\mathrm{M}}$ is defined and deduced as:

$\xi_{\mathrm{M}}=V_{\mathrm{M}} / V=\left(\varepsilon_{\mathrm{X}}-\varepsilon_{M S}\right) / \Delta \varepsilon_{\mathrm{tran}}$,

where $V$ and $V_{\mathrm{M}}$ are the volumes of the total SMA and the martensite phase, respectively. $\varepsilon_{M S}$ is the martensitic start strain, which equals the elastic strain. Multiplying both sides of Equation 2 by the martensitic phase fraction $\xi_{\mathrm{M}}$, and substituting Equations 3, 4, 6 and the linear assumption (Equation 5) into Equation 2, we have

$q\left(\varepsilon_{\mathrm{x}}, \sigma_{\mathrm{x}}\right)+\xi_{\mathrm{M}} \cdot\left[\Delta h(0)+\int_{T_{0}(0)}^{T_{0}(\sigma)}\left(c_{F}^{M}-c_{F}^{P}\right) \cdot d T\right]=\frac{1}{\rho} \frac{\left(\frac{\sigma_{\mathrm{X}}-\sigma_{M S}}{\xi_{\mathrm{M}}}+2 \sigma_{M s}\right)}{2} \cdot\left(\varepsilon_{\mathrm{x}}-\varepsilon_{M S}\right)$.

In the cases of $c_{F}^{P}$ and $c_{F}^{M}$ being identical, Equation 7 is simplified as,

$q\left(\varepsilon_{\mathrm{x}}, \sigma_{\mathrm{x}}\right)+\xi_{\mathrm{M}} \cdot \Delta h(0)=\frac{1}{\rho} \frac{\left(\frac{\sigma_{\mathrm{X}}-\sigma_{M s}}{\xi_{\mathrm{M}}}+2 \sigma_{M s}\right)}{2} \cdot\left(\varepsilon_{\mathrm{x}}-\varepsilon_{M s}\right)$.

Solving the Equation 8, $\xi_{\mathrm{M}}$ is deduced from the results of $\left(q, \varepsilon_{\mathrm{x}}, \sigma_{\mathrm{x}}\right)$ and the DSC result $(\Delta h(0))$. Thus, the latent heat $\Delta h^{*}$ can be derived from the released heat $q\left(\varepsilon_{\mathrm{x}}, \sigma_{\mathrm{x}}\right)$ and phase fraction $\xi_{\mathrm{M}}$ in Equation 8, which is compatible for incomplete phase transformation. From Equation 7 to Equation 8, the ratio of $\int_{T_{0}(0)}^{T_{0}(\sigma)}\left(c_{F}^{M}-c_{F}^{P}\right) \cdot d T$ to $\Delta h(0)$ determine the error of IPTA correction for the SMAs when $c_{F}^{M} \neq c_{F}^{P}$. For the SMAs of $\mathrm{Ni}_{55} \mathrm{Ti}_{45}$ and $\mathrm{Ni}_{48} \mathrm{Ti}_{52},{ }^{[78]}$ the deviations of $c_{F}^{M}$ from $c_{F}^{P}$ are $1 \%$ and $3.3 \%$, therefore the errors of $\xi_{\mathrm{M}}$ are $1.2 \%$ and $3.8 \%$, respectively. Thus, the assumption of $c_{F}^{P}$ and $c_{F}^{M}$ being identical can be made in many Ni-Ti alloys. ${ }^{[70,71,79]}$ The same assumption for the SMAs of $\mathrm{Ti}-\mathrm{Ni}-\mathrm{Cu}-\mathrm{Co}^{[55]}$ and $\mathrm{Ni}-\mathrm{Fe}-\mathrm{Ga}_{-} \mathrm{Co}^{[69]}$ are validated through the comparison of $\left|\Delta h^{*}(\sigma)-w_{\sigma \varepsilon}\right|$ and $|\Delta h(0)|$ in Figure 2(a).

The released heat $q\left(\varepsilon_{\mathrm{x}}, \sigma_{\mathrm{x}}\right)$ can be obtained by the adiabatic temperature change, enthalpy difference of HTF directly or by the Clausius-Clapeyron equation indirectly. ${ }^{[25]} \Delta h^{*}$ is obtained from Equation 3,

This article is protected by copyright. All rights reserved 


$$
\Delta h^{*}=-\underbrace{\frac{1}{\rho} \frac{d \sigma_{c r}}{d T} T \Delta \varepsilon_{\text {tran }}\left(\varepsilon_{\mathrm{x}}-\varepsilon_{M S}\right)}_{\text {Indirect approach }} / \xi_{\mathrm{M}}=-\underbrace{\int_{0}^{t}\left(h_{\text {out }}-h_{\mathrm{in}}\right) d t}_{\text {Direct approach }} / \xi_{\mathrm{M}} \approx-\underbrace{c_{\mathrm{ps}} \Delta T_{\mathrm{adi}}}_{\text {Direct approach }} / \xi_{\mathrm{M}},
$$

where $d \sigma_{c r} / d T$ is the Clausius-Clapeyron slope and $c_{\mathrm{ps}}$ is the sample specific heat.

Practically, the conventional direct and indirect approaches invested much effort to realize complete phase transformation and ignored the martensitic phase fraction (assuming $\xi_{M}=1$ ). From Equation 9, the latent heat $\Delta h^{*}$ from direct and indirect approaches disregarding the phase fraction will be underestimated when phase transformation is not sufficiently saturated. It is worth pointing out that the measurements of $\Delta s_{\text {iso }}$ (for indirect approach), $\left(h_{\text {out }}-h_{\text {in }}\right)$ and $\Delta T_{\text {adi }}$, as inputs for IPTA correction, are dependent on cycle numbers ${ }^{[33]}$ and frequencies ${ }^{[39]}$ that are not included in Equation 9. In order to obtain the $\Delta h^{*}$ in Equation 9, we propose the measurement to be conducted during a single-shot under the possible lowest loading rate (frequencies) or be extrapolated to zero rate. Special attention should be paid in the cases of $\Delta T_{\text {adi }}$ measurement, low loading rates probably result in increasingly heat leakage.

\section{Experiments}

The experimental characterization in this study consists of the DSC, compressive test, elastocaloric test and heat leak evaluation. To approach the isothermal condition, pure water with high thermal mass was used as HTF instead of air. The difficulty of using water arises from the fact that relatively large scale apparatus is needed to match the measurements. Tubular samples are applied in compressive and elastocaloric tests for the purpose of water-tight. The samples are $\mathrm{Ni}_{50.8} \mathrm{Ti}_{49.2} \mathrm{SMAs}$ provided by Xi'an Saite Metal Materials Development, Inc.. Various sample shapes are applied throughout the experiments, which are summarized in Table $\mathbf{1 .}$

Table 1. Properties of the Ni-Ti alloys used in different experiments.

\begin{tabular}{lllll}
\hline \multirow{2}{*}{ Experiments } & Sample & Length & Inner diameter & Outer diameter \\
\cline { 2 - 5 } DSC & Flakes & - & - & - \\
Compressive test & Sample A, tube & $20 \mathrm{~mm}$ & $4 \mathrm{~mm}$ & $5 \mathrm{~mm}$ \\
Elastocaloric test & Sample B, tube & $105 \mathrm{~mm}$ & $3 \mathrm{~mm}$ & $5 \mathrm{~mm}$ \\
Heat leak evaluation & Sample B, tube & $105 \mathrm{~mm}$ & $3 \mathrm{~mm}$ & $5 \mathrm{~mm}$ \\
\hline
\end{tabular}

DSC experiment was conducted to determine the $\Delta h(0)$ in a DSC $204 \mathrm{~F} 1$, Netzsch. The heat This article is protected by copyright. All rights reserved 
calibration of the instrument was conducted using indium, tin and lead-potassium nitrate as reference materials. Other experiments were carried out in an integrated system shown in Figure 3. For the elastocaloric test, the water particle flowed out from a (1) thermal reservoir with a regulated flow rate $\left(\dot{m}_{\mathrm{f}}\right)$ via a (3) Coriolis mass flow meter (SINCERITY DMF-1-3A). The temperature entering the loading area $\left(T_{\mathrm{in}}\right)$ was controlled by a (2) thermostatic bath (JTONE JTDC-0506). Sample B was situated between two (4) stainless steel blocks and the stress was applied horizontally via a (5) mobile plate from a servohydraulic system (INVT MH800). The stress $(\sigma)$ was monitored by a (6) force sensor (LH-S08) and the strain $(\varepsilon)$ was measured by a (7) linear variable differential transformer (LVDT, MIRAN LVDT8-V1-10MM-SL-A-2). At the ambient temperature $\left(T_{\mathrm{am}}\right)$ of $\sim 299 \mathrm{~K}$, the eCE of Sample B was tested under a moderate strain rate of approximately $0.025 \mathrm{~s}^{-1}$ to improve the eCE measurability and reduce the heat leakages. The sample was designed as thick wall and a (8) polyformaldehyde casing pipe to prevent buckling during the compression. The temperature of water exiting the loading area $\left(T_{\text {out }}\right)$ increased by the released heat of the eCE. The loading then lasted for 30 seconds to ensure thermal equilibrium between water and the sample. Then the water particle was pumped by a (9) micro pump (XWC CSP1090) back to the (1) thermal reservoir through a (10) regulating valve. The regulating valve is tuned manually to maintain the $\dot{m}_{\mathrm{f}}$ from the feedback of (3) Coriolis mass flow meter. $T_{\mathrm{in}}$ and $T_{\text {out }}$ are measured by T-type thermocouples, while $T_{\mathrm{am}}$ is measured by a K-type thermocouple.

For the compressive test, Sample A was loaded under a low strain rate of around $4 \times 10^{-4} \mathrm{~s}^{-1}$ and a high mass flow rate to ensure the isothermal condition. ${ }^{[33]}$ A K-type thermocouple was attached to the tube wall to monitor the temperature of $\mathrm{Ni}$-Ti tube $\left(T_{\mathrm{s}}\right)$. To avoid the residual strain during loading and unloading operation, a brand new sample is used for each single test.

The released heat is experimentally determined below:

$q=c_{\mathrm{pf}} \int_{t_{0}}^{t_{\mathrm{f}}} \dot{m}_{\mathrm{f}}\left(T_{\mathrm{out}}-T_{\mathrm{in}}\right) d t / m$,

where $t_{0}$ is the initial time of loading, $t_{\mathrm{f}}$ is the finish time of thermal equilibrium between water and sample, $c_{\mathrm{pf}}$ is the specific heat of water and $m$ is the mass of the sample. During the heat leak evaluation, the sample B was tested under the no-load condition. The heat loss factor $\delta$ is obtained:

$c_{\mathrm{pf}} \dot{m}_{\mathrm{f}} \Delta T_{1}=h A \Delta T_{2}=\delta \Delta T_{2}$

$\Delta T_{1}=T_{\text {out }}-T_{\text {in }}$,

$\Delta T_{2}=\left(T_{\text {out }}+T_{\text {in }}\right) / 2-T_{\text {am }}$,

This article is protected by copyright. All rights reserved 
where $h$ is the overall heat transfer coefficient, $A$ is the overall heat transfer area, $\Delta T_{1}$ is the temperature difference between inflow and outflow HTF, $\Delta T_{2}$ is the temperature difference between the bulk temperature of water and the ambient temperature. $\delta$ can be calculated from the measurements of $T_{\mathrm{in}}, T_{\text {out }}$ and $T_{\mathrm{am}}$. Thus, the released heat $q$ in Equation 10 is modified for the heat leak compensation, by means of updating the values of $T_{\text {out }}$ from average $\delta$ and instantaneous $\Delta T_{1}$.
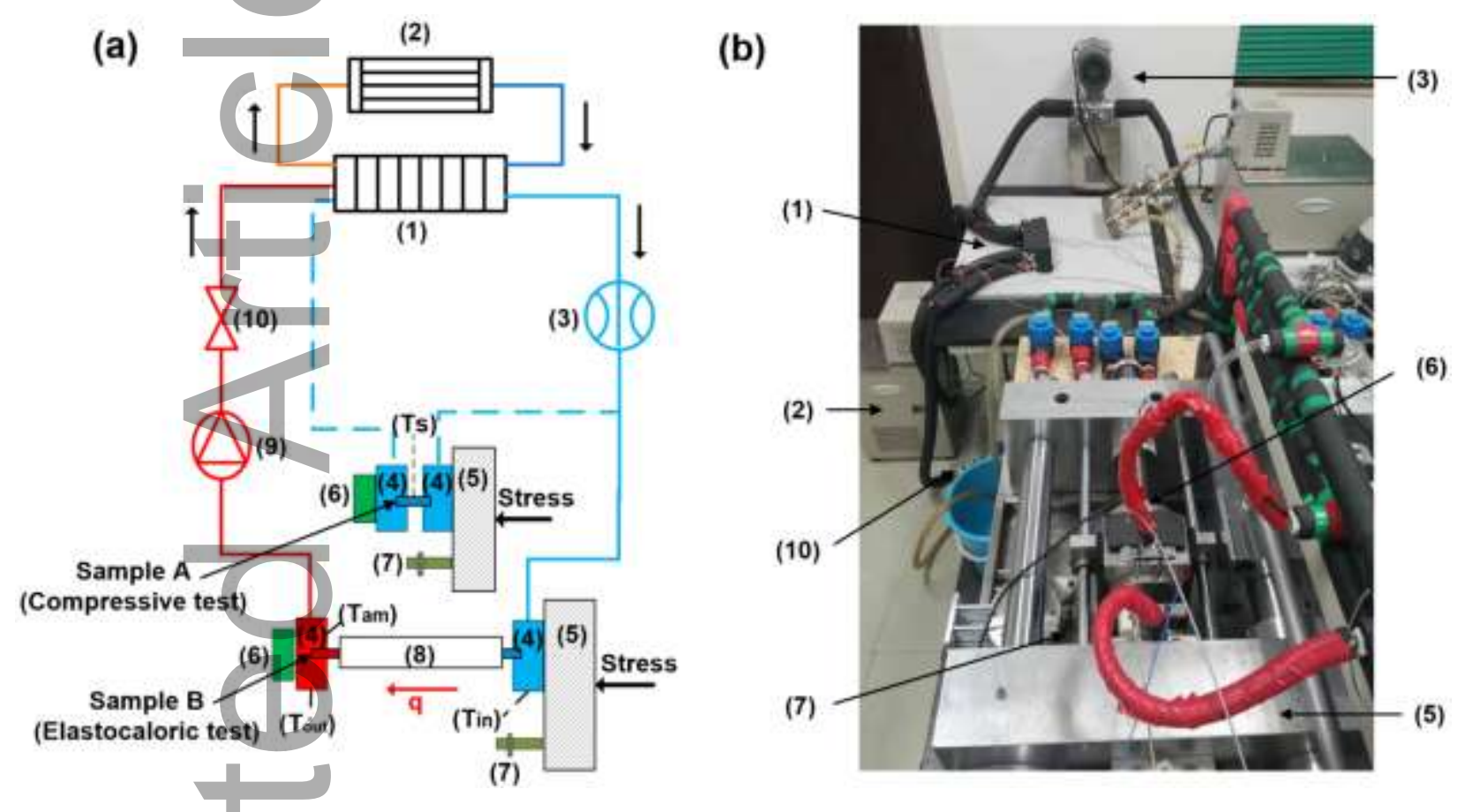

Figure 3. (a) A sketch of the integrated system. (b) The photo of the integrated system involving the part of the elastocaloric test. The main components consist of (1) thermal reservoir (plate heat exchanger), (2) thermostatic bath, (3) mass flow meter, (4) stainless steel block, (5) mobile plate, (6) force sensor, (7) LVDT, (8) polyformaldehyde casing pipe, (9) micro pump and (10) regulating valve.

\section{Results and discussion}

In order to validate the IPTA thoroughly, the latent heat $\Delta h^{*}$ obtained from direct and indirect approaches plugging different corrections are analyzed in Table 2, which involves isothermal or adiabatic condition and imposes air or water as HTF. For the correction of heat leak compensation (HLC), the latent heat $\Delta h^{*}$ will be corrected via a heat loss coefficient in Equation 11. In the case of IPTA, the latent heat $\Delta h^{*}$ will be further derived using the martensitic phase fraction in Equation 9. The applied elastocaloric materials consist of $\mathrm{Ni}_{50.8} \mathrm{Ti}_{49.2}$ (I) in this study and $\mathrm{Ni}_{50.8} \mathrm{Ti}_{49.2}$ (II) from the literature, ${ }^{[59]}$ which are processed from different batches. 
Table 2. Summary of various approaches for obtaining the latent heat $\Delta h^{*}$. The deviations take the benchmark value from literature as a reference.

\begin{tabular}{|c|c|c|c|c|c|c|}
\hline Approaches & HTFs & Conditions & Corrections & Materials & $\begin{array}{l}\text { Minimum } \\
\text { deviation }\end{array}$ & $\begin{array}{l}\text { Mean } \\
\text { deviation }\end{array}$ \\
\hline Dir-ad & Air & Adiabatic & - & $\mathrm{Ni}_{50.8} \mathrm{Ti}_{49.2}(\mathrm{II})$ & $58.6 \%$ & - \\
\hline Indirect & - & Isothermal & - & $\mathrm{Ni}_{50.8} \mathrm{Ti}_{49.2}(\mathrm{I})$ & $26.9 \%$ & - \\
\hline Dir-iso & Water & Isothermal & - & $\mathrm{Ni}_{50.8} \mathrm{Ti}_{49.2}(\mathrm{I})$ & $39.8 \%$ & - \\
\hline Dir-iso-HLC & Water & Isothermal & HLC & $\mathrm{Ni}_{50.8} \mathrm{Ti}_{49.2}(\mathrm{I})$ & $33.6 \%$ & - \\
\hline Dir-ad-IPTA & Air & Isothermal & IPTA & $\mathrm{Ni}_{50.8} \mathrm{Ti}_{49.2}(\mathrm{II})$ & $2.7 \%$ & $6.7 \%$ \\
\hline Ind-IPTA & - & Isothermal & IPTA & $\mathrm{Ni}_{50.8} \mathrm{Ti}_{49.2}(\mathrm{I})$ & $4 \%$ & $6 \%$ \\
\hline Dir-iso-IPTA & Water & Isothermal & IPTA & $\mathrm{Ni}_{50.8} \mathrm{Ti}_{49.2}(\mathrm{I})$ & $14 \%$ & $23 \%$ \\
\hline Dir-iso-HLC-IPTA & Water & Isothermal & HLC and IPTA & $\mathrm{Ni}_{50.8} \mathrm{Ti}_{49.2}(\mathrm{I})$ & $0.4 \%$ & $8.2 \%$ \\
\hline
\end{tabular}

The latent heat $\left|\Delta h^{*}\right|$ for $\mathrm{Ni}_{50.8} \mathrm{Ti}_{49.2}$ (I) derived from different approaches without IPTA correction in Table 2 are analyzed as a function of $\varepsilon_{\mathrm{x}}$ in Figure 4(a). The incorporation of heat leak compensation (HLC) drives the $\varepsilon_{\mathrm{x}} \sim\left|\Delta h^{*}\right|$ relation to the higher linearity and approaching the results from the indirect approach. Taking the indirect approach as a baseline, the Dir-iso-HLC approach deviates around $7 \%$, while the deviation of conventional Dir-iso approach is up to $20 \%$. Thus, the HLC realization improves the accuracy of the direct approaches of the eCE characterization significantly. However in Figure 4(a), both the maximum latent heat $\left|\Delta h^{*}\right|$ in Dir-iso-HLC approach (15 $\mathrm{J} \mathrm{g}^{-1}$ at $6 \%$ strain) and in indirect approach (16.5 $\mathrm{J} \mathrm{g}^{-1}$ at $6 \%$ strain) are smaller than the $|\Delta h(0)|\left(17.29 \mathrm{~J} \mathrm{~g}^{-1}\right)$ from the stress-free DSC result. The discrepancy between the $\left|\Delta h^{*}\right|$ and $|\Delta h(0)|$ is ascribed to the $\sigma \varepsilon$-work shown in Equation 2. It is noted that the effect of incomplete phase transformation is taken into account in the variation of the $\sigma \varepsilon$-work term.

To apply the IPTA in predicting latent heat $\left|\Delta h^{*}\right|$, the mechanical curve of stress and strain is provided in Figure 4(b) from the compressive test, and the data points corresponding to different strain conditions in Figure 4(a) are highlighted as blue markers. Considering the corrections listed in Table 2, the $\left|\Delta h^{*}\right|$ for $\mathrm{Ni}_{50.8} \mathrm{Ti}_{49.2}$ (I) from different approaches are shown as a function of $\varepsilon_{\mathrm{x}}$ in Figure 4(c). The benchmark value of the $\left|\Delta h^{*}\right|$ for the same material is obtained from the indirect 
approach under a complete phase transformation from the published literature. ${ }^{[57]}$ Quantitatively, Ind-IPTA and Dir-iso-HLC-IPTA deviate around $6 \%$ and $8.2 \%$ from the benchmark value, respectively, which shows a good agreement. Nevertheless, the $\left|\Delta h^{*}\right|$ at Dir-iso-IPTA at various $\varepsilon_{\mathrm{x}}$ fluctuate slightly and the mean deviation reaches $23 \%$. Recalling the $\left|\Delta h^{*}\right|$ values at the strain of $6 \%$ in Figure 4(a), the $\left|\Delta h^{*}\right|$ obtained from the indirect, Dir-iso-HLC and Dir-iso approaches without IPTA correction deviate $26.9 \%, 33.6 \%$ and $39.8 \%$ from the benchmark value of $22.6 \mathrm{~J} \mathrm{~g}^{-1}$, respectively. Therefore, the deviations of $\left|\Delta h^{*}\right|$ by IPTA correction in Figure 4(c) are significantly smaller than those in Figure 4(a). Furthermore, when adopting both IPTA and HLC corrections, the prediction of $\left|\Delta h^{*}\right|$ exhibits the deviation of only $8.2 \%$. This implies the significant improvement compared to the conventional direct and indirect approaches.
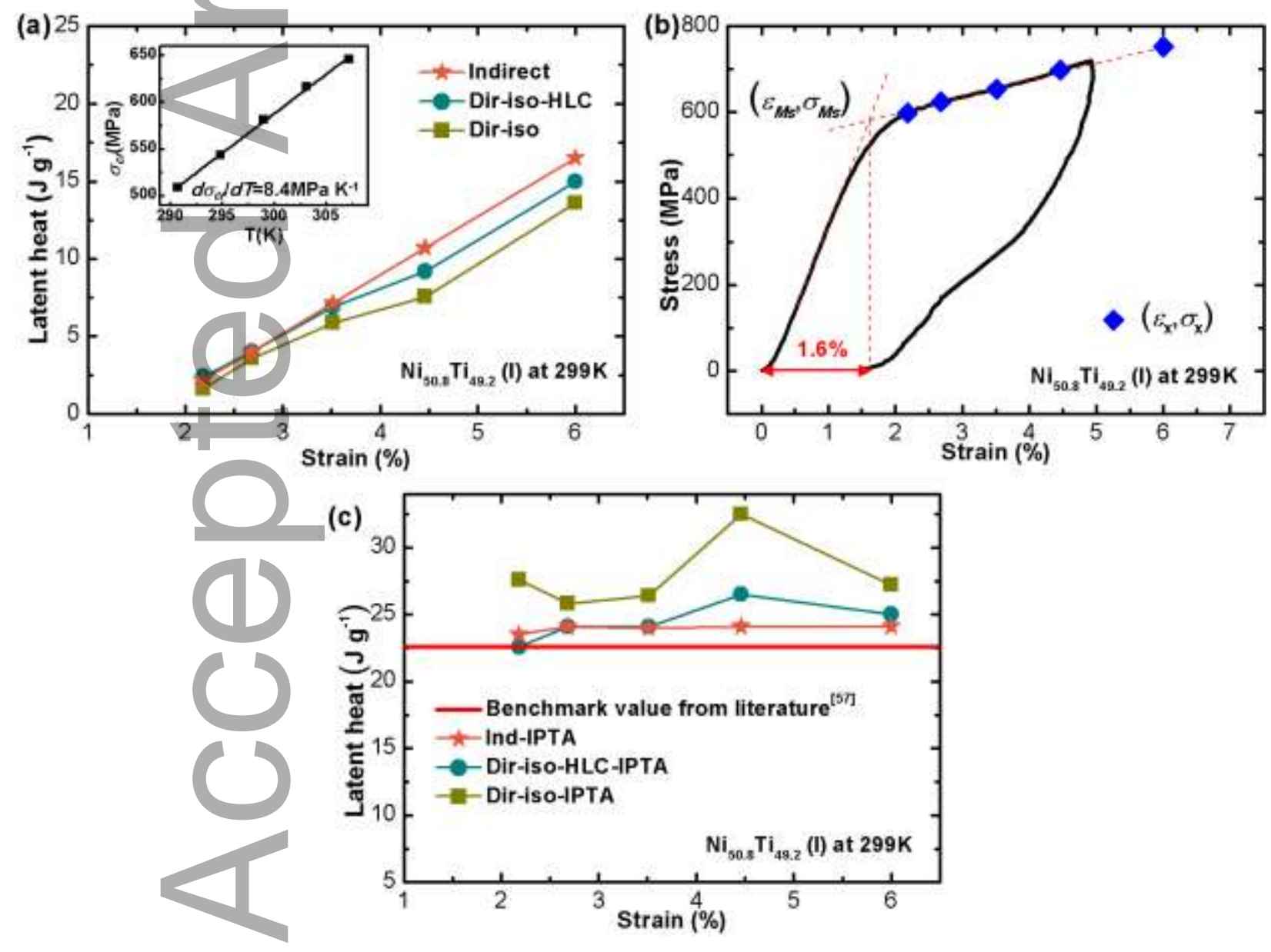

Figure 4. (a) The latent heat $\left|\Delta h^{*}\right|$ obtained by Dir-iso-HLC, Dir-iso and indirect approaches as a function of strain for $\mathrm{Ni}_{50.8} \mathrm{Ti}_{49.2}(\mathrm{I})$ at $299 \mathrm{~K}$. The inset shows the critical stress as a function of temperature. The slope $d \sigma_{c r} / d T$ is 8.4 $\mathrm{MPa} \mathrm{K}^{-1}$. (b) Stress-strain curve from compressive test at $299 \mathrm{~K}$. The marker points $\left(\varepsilon_{\mathrm{x}}, \sigma_{\mathrm{x}}\right)$ are linked to the data points in Figure 4(a). The $\varepsilon_{M S}$ of $1.6 \%$ is determined by the intersection of the tangent lines in the $\sigma(\varepsilon)$ curve. (c) The latent heat $\left|\Delta h^{*}\right|$ obtained by the approaches of Dir-iso-HLC-IPTA, Dir-iso-IPTA and Ind-IPTA as a function 
of strain for $\mathrm{Ni}_{50.8} \mathrm{Ti}_{49.2}(\mathrm{I})$ at $299 \mathrm{~K}$.

To examine the functioning of using water as HTF, Figure 5(a) shows the relative deviations of the $\left|\Delta h^{*}\right|$ between indirect and direct approaches. For a comprehensive comparison, the results of Dir-ad approach from other SMAs experiments are referred to Figure 1(b). Taking the indirect approach as the reference, the deviation in the Dir-ad approach (32.1\%) with air as HTF is larger than that in the approaches of Dir-iso $(20.5 \%)$ and Dir-iso-HLC (7.4\%) with water as HTF, because the larger temperature span in Dir-ad approach likely results in more heat leakage. Thus, using water as HTF is positive to improve the accuracy of the eCE characterization and therefore is beneficial for applying the IPTA correction. In addition, the IPTA is also adoptable for the experimental characterization with air as HTF. Figure 5(b) compares the $\left|\Delta h^{*}\right|$ determined by the Dir-ad-IPTA and the Dir-ad approaches for $\mathrm{Ni}_{50.8} \mathrm{Ti}_{49.2}$ (II) ${ }^{[59]}$ at $267 \mathrm{~K}$. In view of the benchmark value, the deviation of the $\left|\Delta h^{*}\right|$ from the Dir-ad approach is greater than $58.6 \%$ due to the incomplete phase transformation. When incorporating the IPTA, the mean deviation of the $\left|\Delta h^{*}\right|$ is only $6.7 \%$. This result is even better than that of $23 \%$ in Dir-iso-IPTA approach, which is probably attributed to the different conditions of strain and temperature between these two approaches.
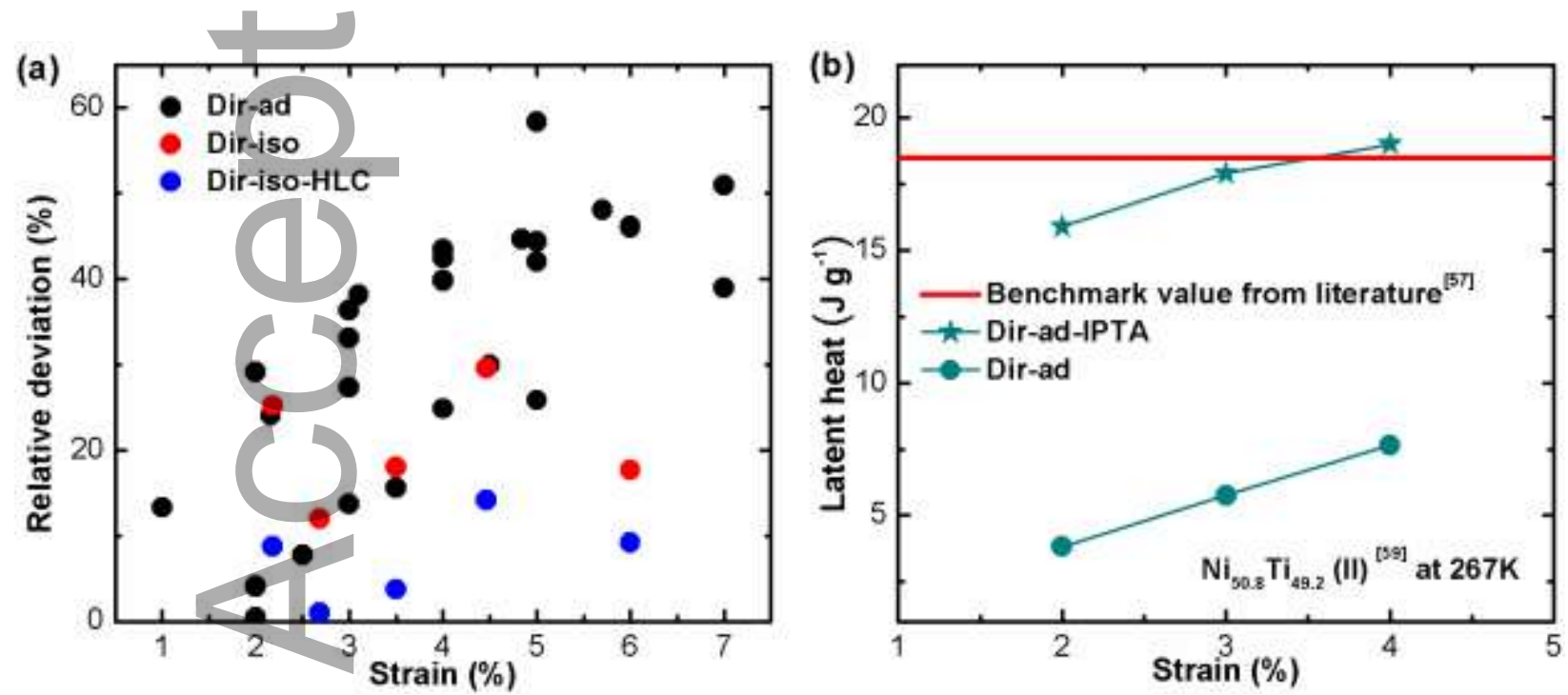

Figure 5. (a) The relative deviations of the $\left|\Delta h^{*}\right|$ between indirect approach and direct approaches influenced by HTF and HLC. (b) The latent heat $\left|\Delta h^{*}\right|$ obtained by Dir-ad and Dir-ad-IPTA approaches as a function of strain for $\mathrm{Ni}_{50.8} \mathrm{Ti}_{49.2}(\mathrm{III})^{[59]}$ at $267 \mathrm{~K}$.

The unique feature of IPTA correction from traditional indirect approach is the consideration of the This article is protected by copyright. All rights reserved 
phase fraction $\xi_{\mathrm{M}}$. When disregarding the $\xi_{\mathrm{M}}$ and therefore the incomplete phase transformation, the indirect approach (Equation 9) likely takes the partial transformation strain $\left(\varepsilon_{\mathrm{x}}-\varepsilon_{M S}\right)$ as the $\Delta \varepsilon_{\text {tran }}$. Due to the practical issues such as buckling before complete phase transformation, the difference between $\left(\varepsilon_{\mathrm{x}}-\varepsilon_{M S}\right)$ and $\Delta \varepsilon_{\text {tran }}$ causes the significant deviation between the $\left|\Delta h^{*}\right|$ and the maximum obtainable $q$. To visualize the difference between indirect approaches with and without IPTA correction, the comparisons of three SMAs are shown in Figure 6. The benchmark values of $\left|\Delta h^{*}\right|$ are obtained from the indirect experiments of complete phase transformation from the published literatures. ${ }^{[57,61]}$ In Figure 6, the y-axis represents the latent heat $\left|\Delta h^{*}\right|$ obtained by indirect and Ind-IPTA approaches in Table 2; while the $\mathrm{x}$-axis denotes the predicted phase fraction $\xi_{\mathrm{M}}$ from Equation 8 using the obtainable $q\left(\varepsilon_{\mathrm{x}}, \sigma_{\mathrm{x}}\right)$ as an input. The $\left|\Delta h^{*}\right|$ obtained from Ind-IPTA approach deviates within $10 \%$ from the benchmark value, which shows a good agreement. From the Figure 6, one can observe what the value of minimum phase fraction is required to impose the $\Delta h^{*}$ prediction in the vicinity of the benchmark value within the error less than $10 \%$. When incorporating IPTA correction, the required minimum phase fraction is only $10-20 \%$ to predict the $\Delta h^{*}$ within $10 \%$ error. In the cases of indirect approach to predict the $\Delta h^{*}$ within $10 \%$ error, the required phase fraction is up to $84.4 \%, 92.9 \%$ and $89.6 \%$ for the SMAs of $\mathrm{Ni}_{50.8} \mathrm{Ti}_{49.2}(\mathrm{I}), \mathrm{Ni}_{50.8} \mathrm{Ti}_{49.2}(\mathrm{II})^{[59]}$ and $\mathrm{Ni}_{54} \mathrm{Fe}_{19} \mathrm{Ga}_{27}{ }^{[61]}$, respectively. This implies that the required minimum martensitic phase fraction for IPTA correction to characterize the latent heat is significantly lower than that in traditional indirect approach. In fact, the IPTA correction is based on the linear assumption of the transformation plateau, which means that the input states $\left(\varepsilon_{\mathrm{x}}, \sigma_{\mathrm{x}}\right)$ are proposed in this linear region. In terms of Figure 4(b), the linear transformation plateau demonstrates a stress range of 580-720 MPa. However, the states $\left(\varepsilon_{\mathrm{x}}, \sigma_{\mathrm{x}}\right)$ near the beginning of martensitic transformation generally deviate from the linear transformation plateau, which will mislead the deduced results from IPTA correction.

This article is protected by copyright. All rights reserved 

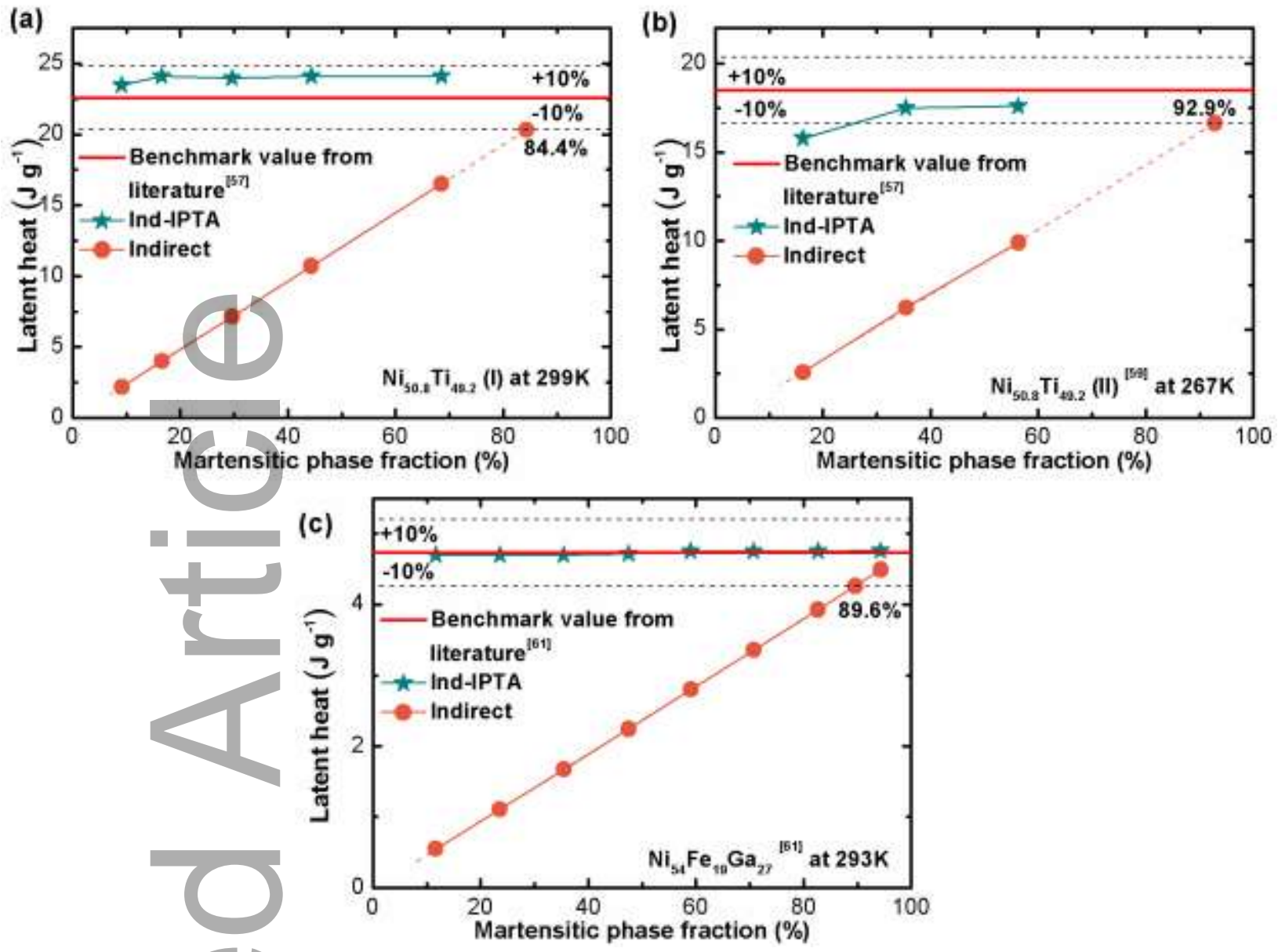

Figure 6. Comparisons of $\left|\Delta h^{*}\right|$ between Ind-IPTA and indirect approaches for the SMAs of (a) $\mathrm{Ni}_{50.8} \operatorname{Ti}_{49.2}$ (I), (b) $\mathrm{Ni}_{50.8} \mathrm{Ti}_{49.2}(\mathrm{II})^{[59]}$ and (c) $\mathrm{Ni}_{54} \mathrm{Fe}_{19} \mathrm{Ga}_{27}{ }^{[61]}$.

\section{Conclusion}

Latent heat of SMAs under complete phase transformation is an important metric for preliminary evaluation of elastocaloric material, which reflects a theoretical obtainable cooling capacity locally in elastocaloric refrigeration. An IPTA correction was developed to characterize the latent heat from the eCE parameters under the incomplete phase transformation. The assumptions of linear transformation plateau in stress-strain curve and heat capacities for austenite and martensite phases being identical $\left(c_{F}^{P}=c_{F}^{M}\right)$ are made and validated for many commonly used SMAs. An integrated test rig, including DSC, compressive test, elastocaloric test and heat leak evaluation, was built to validate this correction and analyze the heat leak effect. Implementing water as HTF and incorporating the HLC experimentally contribute at least $14.8 \%$ more accuracy for the IPTA application. Various direct and indirect approaches applying the IPTA correction show good agreement with the benchmark value from published data. The main advantage of IPTA is obtaining 
the martensitic phase fraction, which is normally disregarded in direct and indirect approaches. The transformation latent heat can be derived from the actual released heat and the martensitic phase fraction. Taking 10\% deviation from the benchmark value as a criterion, the required minimum martensitic phase fractions are only 10-20\% in IPTA applications and up to 84-93\% in conventional indirect approaches, respectively. Thus, applying IPTA correction can provide a reasonable prediction experimentally under an incomplete transformation. This correction also provides a predictable understanding of complete phase transformation for some promising alloys, such as $\mathrm{Cu}$-based SMAs, which fails to accomplish the complete martensitic transformation due to the brittle nature, and shows a reasonable support in the selection of a SMA for an elastocaloric cooling device.

\section{Acknowledgements}

J. Liang is grateful for financial support of the CSC (China Scholarship Council) scholarship. This work was supported by the HCFC phase out management plane in room air conditioning sector technical assistance fund (China), FOSHAN Major Biding Research Program for Domestic and Abroad (2013AH100023) and Midea Group.

\section{REFERENCES}

[1] J. Döntgen, J. Rudolph, T. Gottschall, O. Gutfleisch, D. Hägele, Energy Technology 2018, 6, $1470-1477$.

[2] S. Engelhardt, C. Molin, S. Gebhardt, S. Fähler, K. Nielsch, R. Hühne, Energy Technology 2018, 6, 1526-1534.

[3] P. Lloveras, A. Aznar, M. Barrio, P. Negrier, C. Popescu, A. Planes, L. Mañosa, E. Stern-Taulats, A. Avramenko, N. D. Mathur, Nature communications 2019, 10, 1-7.

[4] S. Patel, A. Chauhan, R. Vaish, Energy Technology 2016, 4, 647-652.

[5] F. Bruederlin, L. Bumke, C. Chluba, H. Ossmer, E. Quandt, M. Kohl, Energy Technology 2018, 6, 1588-1604.

[6] W. Goetzler, R. Zogg, J. Young, C. Johnson, Navigant Consulting Inc., prepared for US Department of Energy 2014.

[7] K. Engelbrecht, J. Phys. Energy. 2019, 1, 021001.

[8] S. A. Nikitin, G. Myalikgulyev, M. P. Annaorazov, A. L. Tyurin, R. W. Myndyev, S. A. Akopyan, Phys. Lett. A 1992, 171, 234-236.

This article is protected by copyright. All rights reserved 
[9] A. Kitanovski, J. Tušek, U. Tomc, U. Plaznik, M. Ozbolt, A. Poredoš, Magnetocaloric energy conversion, Springer, 2016.

[10] A. Smith, C. R. H. Bahl, R. Bjørk, K. Engelbrecht, K. K. Nielsen, N. Pryds, Advanced Energy Materials 2012, 2, 1288-1318.

[11] R. Teyber, J. Holladay, K. Meinhardt, E. Polikarpov, E. Thomsen, J. Cui, A. Rowe, J. Barclay, ApEn 2019, 236, 426-436.

[12] V. K. Pecharsky, K. A. Gschneidner Jr, Physical review letters 1997, 78, 4494.

[13] Y. J. Huang, Q. D. Hu, N. M. Bruno, J.-H. Chen, I. Karaman, J. H. Ross, J. G. Li, Scripta Mater. 2015, 105, 42-45.

[14] S. Lisenkov, I.Ponomareva, Physical Review B 2012, 86, 104103.

[15] J. Tan, Y. Wang, S. Xu, H. Liu, S. Qian, Energy 2020, 197, 117261.

[16] J. A. Barelay, W. A. Steyert, Google Patents, 1982.

[17] F. Bruederlin, L. Bumke, E. Quandt, M. Kohl, in 2019 20th International Conference on Solid-State Sensors, Actuators and Microsystems \& Eurosensors XXXIII (TRANSDUCERS \& EUROSENSORS XXXIII), IEEE, 2019, pp. 1467-1470.

[18] M. Belkadi, A. Smaili, Int. J. Hydrogen Energy 2018, 43, 3499-3511.

[19] R. Snodgrass, D. Erickson, Sci Rep 2019, 9, 1-10.

[20] A. Kitanovski, Advanced Energy Materials 2020, 10, 1903741.

[21] P. Kabirifar, A. Žerovnik, Ž. Ahčin, L. Porenta, M. Brojan, J. Tušek, Strojniški vestnikJournal of Mechanical Engineering 2019, 65, 615-630.

[22] A. Greco, C. Aprea, A. Maiorino, C. Masselli, Int. J. Refrig. 2019, 106, 66-88.

[23] K. Klinar, A. Kitanovski, Renew. Sust. Energ. Rev. 2020, 118, 109571.

[24] S. M. Kirsch, F. Welsch, N. Michaelis, M. Schmidt, A. Wieczorek, J. Frenzel, G. Eggeler, A. Schütze, S. Seelecke, Energy Technology 2018, 6, 1567-1587.

[25] X. Moya, S. Kar-Narayan, N. D. Mathur, Nat. Mater. 2014, 13, 439-450.

[26] J. Tušek, K. Engelbrecht, L. Mañosa, E. Vives, N. Pryds, Shap. Mem. Superel. 2016, 2, 317-329.

[27] V. Franco, J. S. Blázquez, J. J. Ipus, J. Y. Law, L. M. Moreno-Ramírez, A. Conde, Prog. Mater Sci. 2018, 93, 112-232.

[28] K. K. Nielsen, H. N. Bez, L. von Moos, R. Bjork, D. Eriksen, C. R. Bahl, Rev. Sci. Instrum. 2015, 86, 103903.

This article is protected by copyright. All rights reserved 
[29] F. Erbesdobler, C. Bahl, R. Bjørk, K. K. Nielsen, J. Appl. Phys. 2020, 127, 095102.

[30] V. Basso, C. P. Sasso, M. Kupferling, Rev. Sci. Instrum. 2010, 81, 113904.

[31] L. Ianniciello, M. Romanini, L. Mañosa, A. Planes, K. Engelbrecht, E. Vives, Appl. Phys. Lett. 2020, 116, 183901.

[32] Y. Hirayama, R. Iguchi, X.-F. Miao, K. Hono, K.-i. Uchida, Appl. Phys. Lett. 2017, 111, 163901

[33] J. Tušek, K. Engelbrecht, L. P. Mikkelsen, N. Pryds, J. Appl. Phys. 2015, 117, 124901.

[34] H. Ossmer, C. Chluba, M. Gueltig, E. Quandt, M. Kohl, Shap. Mem. Superel. 2015, 1, $142-152$

[35] H. Chen, Y.-D. Wang, Z. Nie, R. Li, D. Cong, W. Liu, F. Ye, Y. Liu, P. Cao, F. Tian, X. Shen, R. Yu, L. Vitos, M. Zhang, S. Li, X. Zhang, H. Zheng, J. F. Mitchell, Y. Ren, Nat. Mater. 2020.

[36] N. Michaelis, A. Schütze, F. Welsch, S.-M. Kirsch, S. Seelecke, Shap. Mem. Superel. 2019, 5, $352-361$.

[37] D. Zhao, J. Liu, X. Chen, W. Sun, Y. Li, M. Zhang, Y. Shao, H. Zhang, A. Yan, Acta Mater. 2017, 133, 217-223.

[38] D. Cong, W. Xiong, A. Planes, Y. Ren, L. Mañosa, P. Cao, Z. Nie, X. Sun, Z. Yang, X. Hong, Y. Wang, Physical Review Letters 2019, 122.

[39] H. Ossmer, F. Lambrecht, M. Gültig, C. Chluba, E. Quandt, M. Kohl, Acta Mater. 2014, 81, 9-20.

[40] J. Tušek, A. Žerovnik, M. Čebron, M. Brojan, B. Žužek, K. Engelbrecht, A. Cadelli, Acta Mater. 2018, 150, 295-307.

[41] Y. Li, D. Zhao, J. Liu, S. Qian, Z. Li, W. Gan, X. Chen, ACS Appl. Mater. Interfaces 2018, 10, $25438-25445$

[42] D. Zhao, F. Xiao, Z. Nie, D. Cong, W. Sun, J. Liu, Scripta Mater. 2018, 149, 6-10.

[43] S. Qian, Y. Wang, Y. Geng, J. Ling, J. Muehlbauer, Y. Hwang, R. Radermacher, I. Takeuchi, in 16th int. Refrig. Air cond. Conf 2016.

[44] J. Tušek, K. Engelbrecht, D. Eriksen, S. Dall'Olio, J. Tušek, N. Pryds, Nat. Energy 2016, 1, 16134

[45] N. Michaelis, F. Welsch, S.-M. Kirsch, M. Schmidt, S. Seelecke, A. Schütze, Int. J. Refrig. 2019, 100, 167-174.

[46] M. Schmidt, A. Schütze, S. Seelecke, APL Mater. 2016, 4, 064107.

This article is protected by copyright. All rights reserved 
[47] E. Vives, S. Burrows, R. S. Edwards, S. Dixon, L. Mañosa, A. Planes, R. Romero, Appl. Phys. Lett. 2011, 98, 011902.

[48] Z. Yang, D. Y. Cong, L. Huang, Z. H. Nie, X. M. Sun, Q. H. Zhang, Y. D. Wang, Materials \& Design 2016, 92, 932-936.

[49] A. Wójcik, W. Maziarz, M. J. Szczerba, M. Sikora, A. Żywczak, C. O. Aguilar-Ortiz, P. Álvarez-Alonso, E. Villa, H. Flores-Zúñiga, E. Cesari, J. Dutkiewicz, V. A. Chernenko, J. Alloys Compd. 2017, 721, 172-181.

[50] X. Zhang, M. Qian, X. Zhu, C. Shang, L. Geng, APL Mater. 2018, 6, 036102.

[51] J. Tušek, K. Engelbrecht, R. Millán-Solsona, L. Mañosa, E. Vives, L. P. Mikkelsen, N. Pryds, Advanced Energy Materials 2015, 5, 1500361.

[52] C. B. Churchill, J. A. Shaw, M. A. Iadicola, ExT 2009, 33, 51-62.

[53] L. Mañosa, S. Jarque-Farnos, E. Vives, A. Planes, Appl. Phys. Lett. 2013, 103, 211904.

[54] G. J. Pataky, E. Ertekin, H. Sehitoglu, Acta Mater. 2015, 96, 420-427.

[55] C. Chluba, H. Ossmer, C. Zamponi, M. Kohl, E. Quandt, Shap. Mem. Superel. 2016, 2, 95-103.

[56] Z. Yang, D. Y. Cong, X. M. Sun, Z. H. Nie, Y. D. Wang, Acta Mater. 2017, 127, 33-42.

[57] Y. Wu, E. Ertekin, H. Sehitoglu, Acta Mater. 2017, 135, 158-176.

[58] M. Zhou, Y.-S. Li, C. Zhang, L.-F. Li, Chin. Phys. B 2018, 27, 106501.

[59] M. Zhou, Y. Li, C. Zhang, S. Li, E. Wu, W. Li, L. Li, J. Phys. D: Appl. Phys. 2018, 51, 135303

[60] H. Chen, F. Xiao, X. Liang, Z. Li, Z. Li, X. Jin, T. Fukuda, Acta Mater. 2019, 177, 169-177.

[61] Y. Li, D. Zhao, J. Liu, Sci Rep 2016, 6, 25500.

[62] M. Imran, X. Zhang, M. Qian, L. Geng, Adv. Eng. Mater. 2020, 1901140.

[63] I. Aaltio, T. Fukuda, T. Kakeshita, J. Alloys Compd. 2019, 780, 930-936.

[64] K. Engelbrecht, J. Tušek, D. Eriksen, T. Lei, C.-Y. Lee, J. Tušek, N. Pryds, J. Phys. D: Appl. Phys. 2017, 50, 424006.

[65] P. Wollants, J. Roos, L. Delaey, Scr. Metall. 1980, 14, 1217-1223.

[66] P. Álvarez-Alonso, C. O. Aguilar-Ortiz, E. Villa, A. Nespoli, H. Flores-Zúñiga, V. A. Chernenko, Scripta Mater. 2017, 128, 36-40.

[67] Y. Sutou, N. Kamiya, T. Omori, R. Kainuma, K. Ishida, K. Oikawa, Appl. Phys. Lett. 2004, 84, $1275-1277$.

This article is protected by copyright. All rights reserved 
[68] P. Wollants, M. De Bonte, J. Roos, Zeitschrift fur metallkunde 1979, 70, 113-117.

[69] F. Xiao, M. Jin, J. Liu, X. Jin, Acta Mater. 2015, 96, 292-300.

[70] X. Zhu, Harbin Institute of Technology 2018.

[71] R. Natalia, B. Sergey, Thermochim. Acta 2015, 602, 30-35.

[72] S. Qian, L. Yuan, J. Yu, G. Yan, Energy 2017, 141, 744-756.

[73] Y. Kim, M.-G. Jo, J.-W. Park, H.-K. Park, H. N. Han, Scripta Mater. 2018, 144, 48-51.

[74] H. Wang, H. Huang, J. Xie, Metals 2017, 7, 527.

[75] Z. Li, Z. Li, J. Yang, D. Li, B. Yang, H. Yan, Z. Nie, L. Hou, X. Li, Y. Zhang, C. Esling, X. Zhao, L. Zuo, Scripta Mater. 2019, 162, 486-491.

[76] A. Shen, D. Zhao, W. Sun, J. Liu, C. Li, Scripta Mater. 2017, 127, 1-5.

[77] T. Fukuda, T. Kakeshita, J. Phys. D: Appl. Phys. 2017, 50, 404003.

[78] J. Smith, R. Lück, Q. Jiang, B. Predel, Journal of phase equilibria 1993, 14, 494-500.

[79] C. Zanotti, P. Giuliani, A. Chrysanthou, Intermetallics 2012, 24, 106-114.

A correction based on incomplete phase transformation is developed to assist characterizing the elastocaloric effect of shape memory alloys. The conventional approaches make extra use of the correction obtain good agreements with the experimental data from a new-built test rig and other published data. The correction extends the precondition of elastocaloric characterization from complete transformation to incomplete transformation.

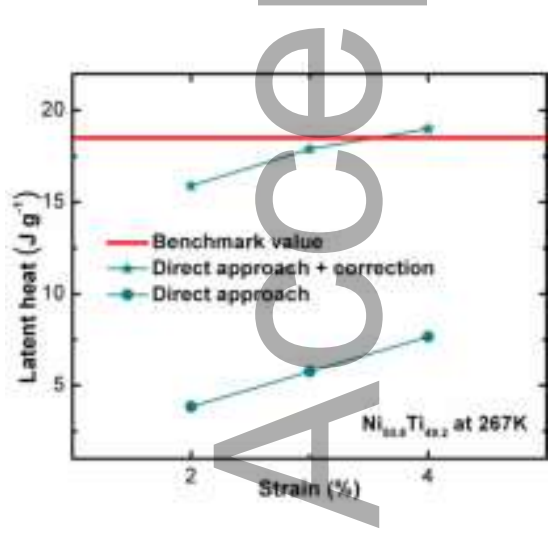

This article is protected by copyright. All rights reserved 